\title{
Non-Viable Lactobacillus johnsonii JNU3402 Protects against Diet-Induced Obesity
}

\author{
Garam Yang ${ }^{1}$, Eunjeong Hong ${ }^{1}$, Sejong $\mathrm{Oh}^{2, *}$ and Eungseok Kim ${ }^{1, *}$ \\ 1 Department of Biological Sciences, College of Natural Sciences, Chonnam National University, \\ Gwangju 61186, Korea; yanggaram@naver.com (G.Y.); okok44554@naver.com (E.H.) \\ 2 Division of Animal Science, College of Agriculture \& Life Sciences, Chonnam National University, \\ Gwangju 61186, Korea \\ * Correspondence: soh@jnu.ac.kr (S.O.); ekim@jnu.ac.kr (E.K.); \\ Tel.: +82-62-530-2116 (S.O.); +82-62-530-3402 (E.K.)
}

Received: 7 September 2020; Accepted: 15 October 2020; Published: 19 October 2020

\begin{abstract}
In this study, the role of non-viable Lactobacillus johnsonii JNU3402 (NV-LJ3402) in diet-induced obesity was investigated in mice fed a high-fat diet (HFD). To determine whether NV-LJ3402 exhibits a protective effect against diet-induced obesity, 7-week-old male C57BL/6J mice were fed a normal diet, an HFD, or an HFD with NV-LJ3402 for 14 weeks. NV-LJ3402 administration was associated with a significant reduction in body weight gain and in liver, epididymal, and inguinal white adipose tissue (WAT) and brown adipose tissue weight in HFD-fed mice. Concomitantly, NV-LJ3402 administration to HFD-fed mice also decreased the triglyceride levels in the plasma and metabolic tissues and slightly improved insulin resistance. Furthermore, NV-LJ3402 enhanced gene programming for energy dissipation in the WATs of HFD-fed mice as well as in 3T3-L1 adipocytes with increased peroxisome proliferator-activated receptor- $\gamma(\operatorname{PPAR} \gamma)$ transcriptional activity, suggesting that the PPAR $\gamma$ pathway plays a key role in mediating the anti-obesity effect of NV-LJ3402 in HFD-fed mice. Furthermore, NV-LJ3402 administration in HFD-fed mice enhanced mitochondrial levels and function in WATs and also increased the body temperature upon cold exposure. Together, these results suggest that NV-LJ3402 could be safely used to develop dairy products that ameliorate diet-induced obesity and hyperlipidemia.
\end{abstract}

Keywords: non-viable Lactobacillus johnsonii JNU3402; diet-induced obesity; peroxisome proliferator-associated receptor- $\gamma$; body temperature

\section{Introduction}

High-caloric intake and low physical activity promote excessive fat accumulation in metabolic tissues including adipose tissues, which is the main cause of obesity and associated metabolic disorders, such as insulin resistance, diabetes, nonalcoholic hepatic steatosis, hyperlipidemia, and cardiovascular disease [1].

Probiotics are living microorganisms that confer a health benefit to the host. Accumulating evidence shows that probiotics remodel the gut-microbiome and signaling pathways whose functioning is altered in response to metabolic imbalances, thereby helping to recover metabolic and immune functions [2]. Recent studies have shown that some Lactobacillus strains protect against diet-induced obesity in mice. Lactobacillus acidophilus NS1 inhibits obesity in high-fat diet (HFD)-fed mice by increasing hepatic fatty acid oxidation with decreased lipogenesis, improving HFD-induced insulin resistance, nonalcoholic fatty liver disease, and hyperlipidemia [3]. In addition, another Lactobacillus strain, Lactobacillus amylovorus KU4, promotes the browning of WAT in HFD-fed mice, leading to the suppression of HFD-induced adiposity with reduced lipid deposition in metabolic tissues, such as liver and WAT as 
well as improved insulin sensitivity [4]. The World Health Organization and the Food and Agriculture Organization of the United Nations define probiotics as living beneficial microorganisms [5]. However, several studies have recently reported that nonliving microorganisms may also have beneficial health effects, such as enhanced immune function and reduced diarrhea [6]. Therefore, non-viable (NV) probiotic bacteria have been garnering increasing interest by virtue of their health benefits, which are known to be similar to those of regular probiotics [7]. Furthermore, NV probiotics are not encumbered by risks associated with live microorganisms and are easier to handle than regular probiotics [7]. Contrary to popular belief, the dairy industry has leveraged the concept of NV probiotics for centuries. The availability of dairy products and other foods increases upon using NV probiotics. Although inactivated starter organisms are used in yogurt due to their ability to increase the shelf life [8], they are empirically understood to have unknown health effects.

Lactobacillus johnsonii was first classified with L. acidophilus and is often isolated from the intestines of humans and animals [9]. Probiotic characteristics are presented by various L. johnsonii strains, including the inhibition of pathogens in the gut, alleviation of diabetes symptoms, reduction of serum cholesterol levels, immune-stimulation, and adhesion to intestinal epithelial cells [10-12]. L. johnsonii JNU3402 (LJ3402) isolated from Korean infant feces exhibit bile and acid resistance. The protective effects of NV Lactobacillus strains against diet-induced obesity have largely remained unexplored. Therefore, the effect of NV-LJ3402 on diet-induced obesity was determined using HFD-fed mice. This study demonstrated that NV-LJ3402 enhanced the expression of the metabolic genes involved in energy expenditure, partly by stimulating the proliferator-associated receptor- $\gamma$ (PPAR $\gamma$ ) activity and mitochondrial levels in WAT, increasing the body temperature and resulting in protection from diet-induced obesity.

\section{Materials and Methods}

\subsection{Preparation of NV-LJ3402}

NV-LJ3402 was prepared using the following method. LJ3402 cells were cultured in MRS broth (BD, Difco Laboratories, Detroit, MI, USA) at $37^{\circ} \mathrm{C}$ for $24 \mathrm{~h}$ and then the cells were centrifuged to $4000 \times$ $g$ for $15 \mathrm{~min}$ at $4{ }^{\circ} \mathrm{C}$. After that, the pellets were then washed 3 times with sterile Phosphate-buffered saline (PBS, $0.01 \mathrm{M}, \mathrm{pH} 7.2$ ) and resuspended to reach a density of ca. $1 \times 10^{8}$ or $1 \times 10^{9} \mathrm{cfu} / \mathrm{mL}$. Normalized cells were killed at $80^{\circ} \mathrm{C}$ for $15 \mathrm{~min}$ in a water bath and the lack of bacterial colonies were confirmed using MRS agar (BD, Difco Laboratories, Detroit, MI, USA) plates.

\subsection{Animals}

Six-week-old C57BL/6J male mice (weight, 19-20 g, Central Animal Laboratory, Daejeon, Korea) were acclimated for 1 week and then fed either a normal diet (16\% of total calories from fat, LabDiet, St. Louis, MO, USA) or HFD (45\% of total calories from fat, Research Diets Inc., New Brunswick, NJ, USA). Two-hundred microliters of NV-LJ3402 resuspension or PBS was orally administered daily to the mice for 14 weeks. All animal procedures were approved by the Institutional Animal Care and Use Committees at Chonnam National University (CNU IACUC-YB-2019-06, Approved date: 19 February 2019).

\subsection{Cell Culture and Transfection}

HEK293T and 3T3-L1 cells were cultured in Dulbecco's Modified Eagle Medium containing 5\% fetal bovine serum or $10 \%$ newborn calf serum and antibiotics. Plasmids, pGL3-UCP1 promoter (-2620 to +68 bp), pGL3-ACOX-PPRE-Luc, pGL3-CETP-LXRE-Luc, pGL3-TK-IR-1-Luc, pCDNA3-PPAR $\gamma$, pCMX-RXR $\alpha, p C M X-L X R$, and pSG5-FXR have been described previously [3,13-15]. MRS broth was heated at $80^{\circ} \mathrm{C}$ for $15 \mathrm{~min}$ and used as a control bacterial culture medium (con). NV-LJ3402-CM or con was added to 3T3-L1 adipocytes on day 6 for $48 \mathrm{~h}$ at 1/100 volume of the medium to test the effect of NV-LJ3402-CM on gene expression, mitochondrial levels, and lipid accumulation. In addition, 
NV-LJ3402-CM was added to HEK293T cells for $24 \mathrm{~h}$ to test its effect on the activities of transcription factors. Adipocyte differentiation of 3T3-L1 cells and transfections were performed as previously described [4].

\subsection{Plasma and Tissue Analyses}

The plasma and tissue levels of triglyceride (TG) and insulin were measured using a TG quantification kit (SCG Biomax, Seoul, Korea) and insulin ELISA (ALPCO, Salem, NH, USA), respectively, according to the manufacturer's protocol. After $8 \mathrm{~h}$ of fasting, mice were injected intraperitoneally with glucose $(1.5 \mathrm{~g} / \mathrm{kg} \mathrm{BW})$ for the glucose tolerance test. Blood glucose levels were measured by tail bleeding.

\subsection{Analyses of Mitochondrial DNA and Citrate Synthase Activity}

DNA was isolated from WATs and 3T3-L1 adipocytes using a genomic DNA isolation kit (Qiagen, Valencia, CA, USA or GeneAll biotechnology, Seoul, Korea) and quantitative PCR was performed to determine mitochondrial DNA (mtDNA) copy number using mtDNA primers and nuclear DNA primers. The fold ratio of mitochondrial DNA levels relative to nuclear DNA was calculated. Citrate synthase activity was measured in WATs and 3T3-L1 adipocytes using a citrate synthase activity assay kit (BioVision, Milpitas, CA, USA).

\subsection{RNA Isolation, Reverse Transcription, and RT-qPCR}

Total RNA was isolated from 3T3-L1 cells and WATs using Trizol reagent (Invitrogen, Waltham, MA, USA), and cDNA was synthesized from $1 \mu \mathrm{g}$ total RNA using Moloney Murine Leukemia Virus (M-MLV)Reverse Transcriptase (Promega, Madison, WIS, USA). Real time-quantitative PCR (RT-qPCR) was performed as previously described [4], and the results were normalized to 36B4 mRNA expression. Relative quantification of PCR products was calculated by the difference in $\mathrm{Ct}$ values between the target and 36B4 genes using the $2^{-\Delta \Delta C t}$ method. Primer sequences for PCR are listed in Table 1.

Table 1. Primers used for the Real time-quantitative PCR (RT-qPCR).

\begin{tabular}{|c|c|c|}
\hline Gene & $5^{\prime}-$ Sense Primer- $3^{\prime}$ & $5^{\prime}$-Antisense Primer- $3^{\prime}$ \\
\hline FAS & AGATCCTGGAACGAGAACACGAT & GAGACGTGTCACTCCTGGACTTG \\
\hline Acc & GTATGTTCGAAGGGCTTACATTG & TGGGCAGCATGAACTGAAATT \\
\hline SREBP1c & ACTGTGACCTCACAGGTCCA & GGCAGTTTGTCTGTGTCCACA \\
\hline ACOX & TCGAGGCTTGGAAACCACTG & TCGAGTGATGAGCTGAGCC \\
\hline CPT1 & ACTCCTGGAAGAAGAAGTTC & TAGGGTCCGATTGATCTTTG \\
\hline PGC1 $\alpha$ & GAGACTTTGGAGGCCAGCA & CGCCATCCCTTAGTTCACTGG \\
\hline UCP1 & GGAGGTGTGGCAGTGTTC & TCTGTGGTGGCTATAACTCTG \\
\hline $\operatorname{PPAR} \gamma$ & GAAGACCACTCGCATTCCTT & GAAGGTTCTTCATGAGGCCTG \\
\hline Cidea & ATCACAACTGGCCTGGTTACG & TACTACCCGGTGTCCATTTCT \\
\hline 36B4 & AGATGCAGCAGATCCGCAT & ATATGAGGCAGCAGTTTCTCCAG \\
\hline D-loop & AATCTACCATCCTCCGTG & GACTAATGATTCTTCACCGT \\
\hline GAPDH & GTTGTCTCCTGCGACTTCA & GGTGGTCCAGGGTTTCTTA \\
\hline
\end{tabular}

\subsection{Yogurt Fermentation}

Homogenized whole milk ( $3.4 \%$ fat, $8.5 \%$ milk solid-non-fat, SNF) and skim milk powder $(0.1 \%$ fat, $95 \%$ SNF) were obtained from a local dairy plant (Seoul Dairies, Seoul, Korea). Skim milk powder was added at a level of $2.5 \%$ to increase milk solids (11\% SNF). One liter of milk base was heated at $95^{\circ} \mathrm{C}$ in a glass bottle (Schott Duran, Germany) for $10 \mathrm{~min}$ and then cooled to $42^{\circ} \mathrm{C}$. Yogurt starters were inoculated with Streptococcus thermophilus (ca. $5 \times 10^{6} \mathrm{cfu} / \mathrm{mL}$, Chr. Hansen Holdings A/S, Hoersholm, Denmark) and L. delbruekii subsp. bulgaricus (ca. $5 \times 10^{6} \mathrm{cfu} / \mathrm{mL}$, Chr. Hansen Holdings A/S). After that, NV-LJ3402 $\left(10^{8}\right.$ and $\left.10^{9}\right)$ was added to the experimental group and then fermented at $42{ }^{\circ} \mathrm{C}$ until the $\mathrm{pH}$ reached 4.5 [16]. 


\subsection{Viable Cells and $\mathrm{pH}$ Measurements}

The $\mathrm{pH}$ values were monitored using a Multi-Channel $\mathrm{pH} / \mathrm{Ion}$ meter with a temperature probe (PhysioLab, Pusan, Korea) and recorded every 60 s during the fermentation process. Viable cells of L. delbrueckii subsp. bulgaricus were enumerated using MRS agar (BD, Difco Laboratories, Detroit, MI, USA) adjusted to $\mathrm{pH} 5.4$ and incubated anaerobically at $37^{\circ} \mathrm{C}$ for $48 \mathrm{~h}$. For enumeration of S. thermophilus, diluted samples were incubated at $43{ }^{\circ} \mathrm{C}$ for $24 \mathrm{~h}$ using M17 agar (BD).

\subsection{Statistical Analysis}

All values are expressed as mean \pm S.E.M. Statistical significance of data was determined by Student's $t$-test for comparisons between two groups, namely, ND vs. HFD groups, HFD vs. HFD-NV-LJ3402 groups in mice, con vs. NV-LJ3402-CM groups, and PPAR $\gamma$ vs. PPAR $\gamma+N V-L J 3402-C M$ groups in 3T3-L1 adipocytes. Statistical differences in gene expression and lipid accumulation among different treatment groups in 3T3-L1 adipocytes were analyzed by Tukey's multiple comparison test using SAS software (Version 9.4, SAS Institute, Cary, NC, USA). $p$ less than 0.05 were considered statistically significant.

\section{Results}

\subsection{Effect of NV-LJ3402 on HFD-Induced Body Weight Gain and Adiposity in Mice}

Recent studies in mice and human volunteers showed that several strains of probiotic bacteria, such as Lactobacillus acidophilus NS1, Lactobacillus amylovorus KU4, and Akkermansia muciniphila, ameliorate obesity and associated metabolic disorders [3,4,17]. To determine whether NV probiotic bacteria have a similar effect on the reduction of diet-induced obesity, 7-week-old male mice were fed HFD with or without oral administration of NV-LJ3402 for 14 weeks. Administration of NV-LJ3402 to HFD-fed mice (NV-LJ3402 mice) reduced HFD-induced body weight gain by 10\% (HFD, $39.79 \pm 1.04 \mathrm{~g}$ vs. NV-LJ3402, $35.95 \pm 1.01 \mathrm{~g}, p<0.05)$ in parallel with a reduction in liver weight $(14 \%, \mathrm{HFD}, 1.63 \pm$ $0.07 \mathrm{~g}$ vs. NV-LJ3402, $1.37 \mathrm{~g} \pm 0.04 \mathrm{~g}, p<0.05$ ), epididymal WAT (eWAT, 26\%, HFD, $1.24 \pm 0.05 \mathrm{~g}$ vs. NV-LJ3402, $0.92 \mathrm{~g} \pm 0.05 \mathrm{~g}, p<0.01$ ), inguinal WAT (iWAT, 30\%, HFD, $1.27 \pm 0.09 \mathrm{~g}$ vs. NV-LJ3402, 0.90 $\mathrm{g} \pm 0.06 \mathrm{~g}, p<0.01)$, and brown adipose tissue weight $(30 \%, \mathrm{HFD}, 0.21 \pm 0.01 \mathrm{~g}$ vs. NV-LJ3402, $0.15 \mathrm{~g} \pm$ $0.01 \mathrm{~g} ; p<0.01$ ), compared to those in HFD-fed mice (HFD mice) (Figure 1a,c). However, there was no significant difference in food intake between these two groups (Figure 1b). Furthermore, TG levels in eWAT and liver in NV-LJ3402 mice were reduced by $36 \%(34.87 \pm 0.74 \mathrm{mg} / \mathrm{g}$ eWAT, $p<0.01)$ and $70 \%$ $(8.84 \pm 1.60 \mathrm{mg} / \mathrm{g}$ liver, $p<0.01)$, respectively, as compared with those $(55.43 \pm 3.01 \mathrm{mg} / \mathrm{g}$ eWAT and $17.09 \pm 1.27 \mathrm{mg} / \mathrm{g}$ liver) in HFD-fed mice (HFD mice) (Figure 1d). As expected, plasma levels of TG were distinctly increased in response to HFD. However, when NV-LJ3402 was administered during HFD feeding, plasma TG levels in HFD mice were reduced by 20\% (HFD, $1.71 \pm 0.05 \mathrm{mmol} / \mathrm{L}$ vs. NV-LJ3402, $1.33 \pm 0.07 \mathrm{mmol} / \mathrm{L}, p<0.01$ ), indicating that the NV-LJ3402 administration confers resistance to HFD-induced obesity and lipid accumulation in the metabolic tissues. Since diet-induced obesity is closely associated with insulin resistance, the possible effect of NV-LJ3402 on insulin resistance was determined. As expected, HFD increased the postprandial and fasting plasma glucose levels by 1.5-fold and 2-fold, respectively, compared to those in ND-fed mice ( $p<0.01$, Figure 1e). However, when NV-LJ3402 was administered to HFD mice, fed and fasting plasma glucose levels and plasma insulin levels were reduced to $26 \%(p<0.05), 40 \%(p<0.05)$, and 51\% $(p<0.05)$, respectively, when compared to those in HFD mice. Next, glucose tolerance was compared between HFD and NV-LJ3402 mice. As expected, intraperitoneal glucose injections increased plasma glucose levels in both HFD and NV-LJ3402 mice to a similar level (Figure 1e). The area under the curve (AUC) analysis for the glucose tolerance test showed that NV-LJ3402 mice exhibited slightly lower glucose levels than HFD mice. However, the glucose-lowering effect of NV-LJ3402 was not statistically significant ( $p=0.0934$ vs. HFD). NV-LJ3402 administration reduced plasma glucose levels after 45 min after glucose injection. 
This NV-LJ3402-mediated reduction in plasma glucose levels became significant $90 \mathrm{~min}$ after glucose injection, while the plasma glucose levels in HFD-fed mice did not significantly change until this time.

(a)

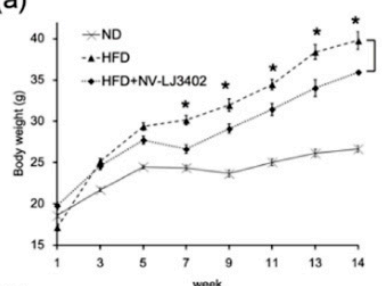

(d)

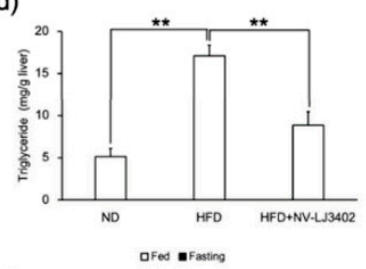

(e)

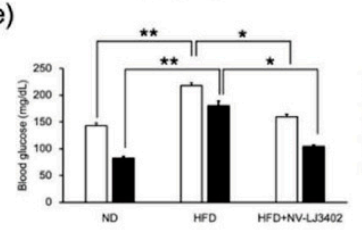

(b)
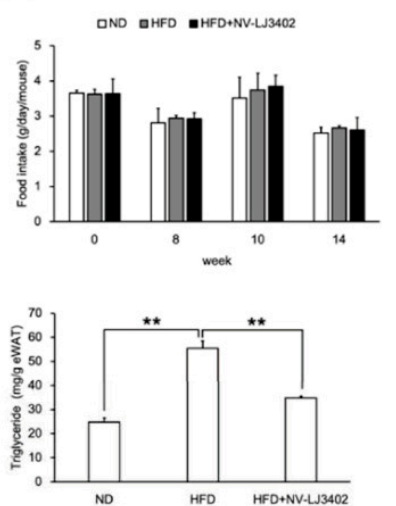

(c)
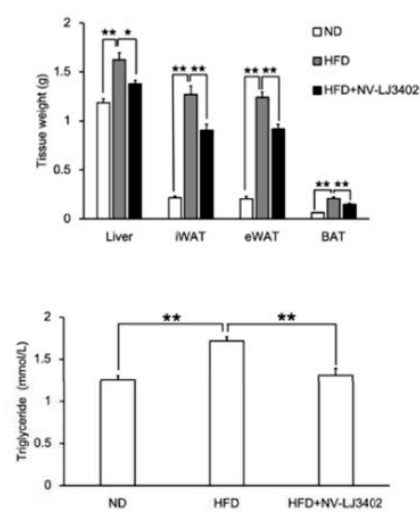

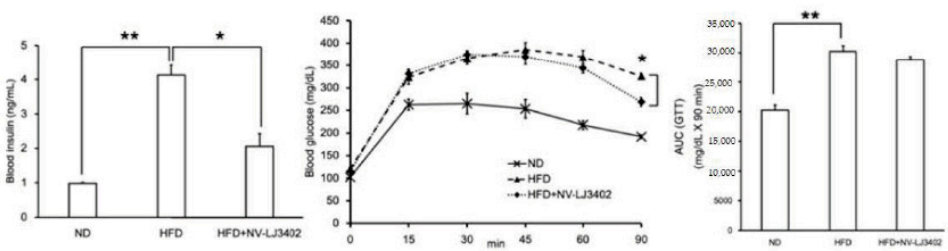

Figure 1. Non-viable Lactobacillus johnsonii JNU3402 (NV-LJ3402) attenuates diet-induced obesity in high fat diet (HFD)-fed mice. Seven-week-old C57BL/6J male mice were administered NV-LJ3402 or Phosphate-buffered saline (PBS) daily for 14 weeks during feeding with a normal diet (ND) or an HFD, and body weight gain (a) of mice was measured as indicated. ( $n=7$ per group). HFD vs. HFD+NV-LJ3402, $* p<0.05$. Daily Food intake (b) was measured three times per indicated week, and tissue weights at the 14 th week of feeding (c) were measured (B-C, $n=6-7$ per group). (d) Triglyceride (TG) levels in the tissues (liver and epididymal WAT (eWAT)) and plasma ( $n=6-7$ per group). (e) Plasma glucose, insulin levels, and glucose tolerance test results from each group of mice after 14 weeks of feeding ( $n=7$ per group). All data are expressed as the mean \pm S.E.M. ND vs. HFD, HFD vs. HFD+NV-LJ3402, ${ }^{*} p<0.05,{ }^{* *} p<0.01$.

\subsection{Effect of NV-LJ3402 on the Expression of Metabolic Genes in the WAT of HFD Mice and 3T3-L1 Adipocytes}

HFD leads to the dysregulation of genes involved in lipid metabolism in metabolic tissues such as WAT, and these alterations in the metabolic gene profile are closely associated with obesity and related metabolic diseases [18]. Therefore, to identify the metabolic pathway underlying the protective effect of NV-LJ3402 against HFD-induced obesity, RT-qPCR was performed to determine the expression profile of genes coding for proteins involved in lipid metabolism in the WAT. NV-LJ3402 reduced the mRNA levels of lipogenic genes, such as fatty acid synthase (FAS), acetyl-CoA carboxylase (ACC), and sterol regulatory element-binding protein-1c (SREBP1c), compared with those in eWAT of HFD mice $(p<0.05)$. Conversely, NV-LJ3402 increased the mRNA levels of genes coding for proteins involved in beta-oxidation, such as acetyl-CoA oxidase (ACOX), carnitine palmitoyltransferase 1 (CPT1), and peroxisome proliferator-activated receptor gamma coactivator $1-\alpha$ (PGC1 $\alpha$ ) in eWAT of HFD mice $(p<0.05$ vs. HFD, Figure 2a). Furthermore, NV-LJ3402 mice also exhibited increased mRNA levels of browning genes in iWAT ( $p<0.05)$, such as uncoupling protein 1 (UCP1), PPAR $\gamma$, and Cidea when compared with those in eWAT of HFD mice. Additionally, when day 6 3T3-L1 adipocytes (day 6 after differentiation) were treated with NV-LJ3402-CM for $48 \mathrm{~h}$, the mRNA levels of genes coding for proteins regulating energy dissipation (UCP1, PPAR $\gamma$, Cidea, ACOX, CPT1, and PGC1 $\alpha$ ) were significantly increased ( $p<0.05$ or $p<0.01$ vs. con) in parallel with the reduction in mRNA levels of lipogenic genes (FAS, ACC, and SREBP1c, $p<0.05$ vs. con, Figure 2b). Since NV-LJ3402 showed a regulatory effect with respect to the expression of genes involved in lipid metabolism, we next analyzed whether 
NV-LJ3402 could inhibit lipid accumulation in 3T3-L1 adipocytes by Oil Red O staining. When 3T3-L1 adipocytes were treated with NV-LJ3402-CM, lipid accumulation on day 8 progressively reduced depending on the treatment duration $(22 \%, 46 \%$, and $61 \%$ decrease after 24,36 , and $48 \mathrm{~h}$ treatment, respectively), compared to that in the control adipocytes ( $p<0.01$ or $p<0.001$, Figure $2 c)$. Together, these results suggest that NV-LJ3402 might reduce lipid accumulation by regulating genes coding for proteins involved in lipid metabolism and browning, leading to reduced adiposity in HFD mice.

(a)

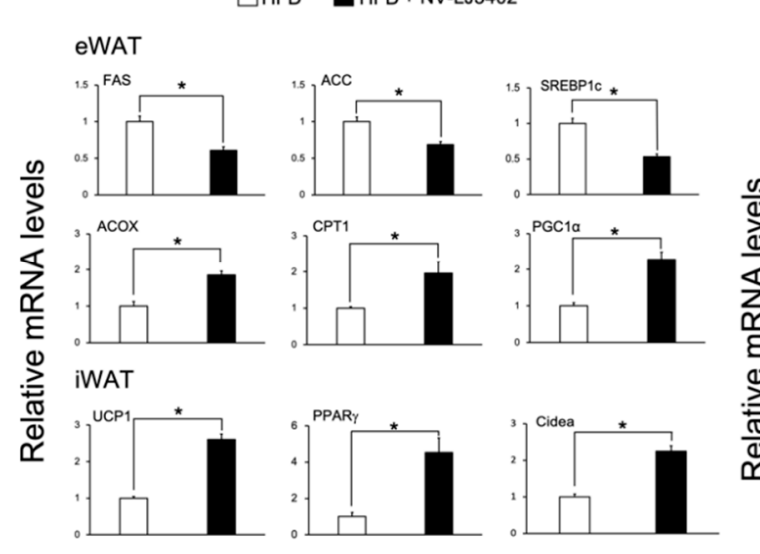

(c)

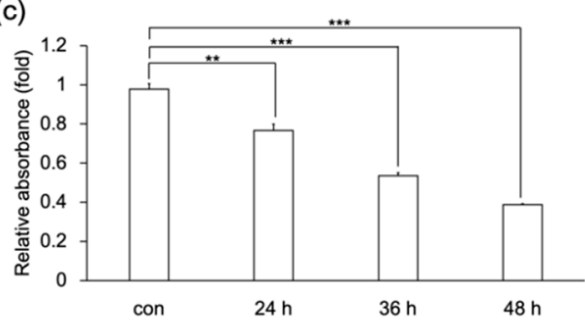

(b)

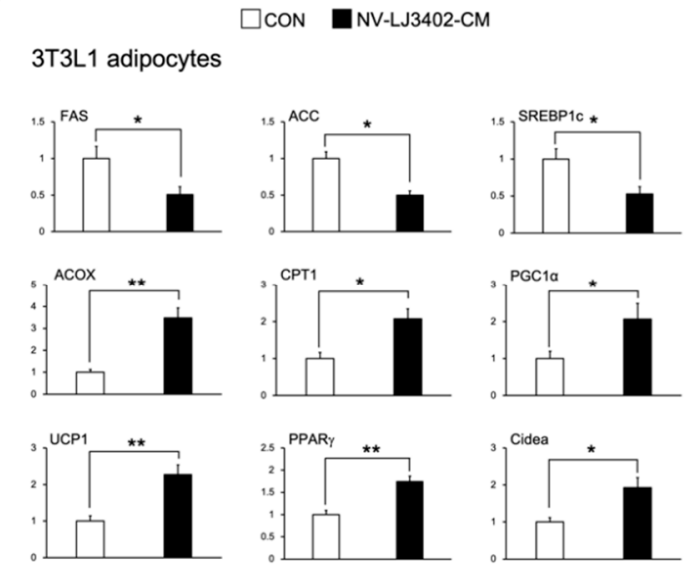

Figure 2. The effect of NV-LJ3402 on metabolic gene expression in the WATs of HFD-fed mice and 3T3-L1 adipocytes. After 14 weeks of NV-LJ3402 administration to HFD mice or 48-h treatment of day 6 3T3-L1 adipocytes with NV-LJ3402-CM or control bacterial culture medium (con), the expression of genes coding for proteins involved in lipogenesis and energy dissipation in WATs (a) and 3T3-L1 adipocytes (b) were determined by Real time-quantitative PCR (RT-qPCR), as indicated. (c) 3T3-L1 adipocytes were treated with NV-LJ3402-CM for different time periods, as indicated. Lipid accumulation in 3T3-L1 adipocytes was analyzed on day 8 by Oil Red O staining. All data are expressed as the mean \pm S.E.M. The experiments using WATs were performed with $n=6-7$ per group, and the results using 3T3-L1 adipocytes are from three independent experiments. HFD vs. HFD+NV-LJ3402, con vs. NV-LJ3402-CM, ${ }^{*} p<0.05,{ }^{* *} p<0.01,{ }^{* * *} p<0.001$.

\subsection{NV-LJ3402 Regulates the Expression of Metabolic Genes by Promoting PPAR $\gamma$ Transcriptional Activity}

NV-LJ3402 has been shown to alter the expression of genes coding for proteins involved in lipid metabolism in the WAT of HFD mice and 3T3-L1 adipocytes. To determine whether NV-LJ3402 regulates the expression of these metabolic genes by controlling the activity of transcription factors that play a key role in adipocyte biology, reporter gene assays were performed in HEK293T cells using reporter genes harboring binding sites of these transcription factors. As expected, all transcription factors tested were activated by their cognate ligands (Figure 3a). However, while NV-LJ3402-CM increased the PPAR $\gamma$ transcriptional activity, NV-LJ3402-CM did not significantly affect the transcriptional activities of liver $\mathrm{X}$ receptor and farnesoid $\mathrm{X}$ receptor, suggesting that NV-LJ3402-CM specifically enhances PPAR $\gamma$ activity to mediate its effect on the expression of genes involved in lipid metabolism. Next, to further confirm the induction of PPAR $\gamma$ transcriptional activity by NV-LJ3402, two other reporter genes harboring the promoter element of either PPAR $\gamma$ or UCP1 were used. As shown in Figure 3b, 
NV-LJ3402-CM increased PPAR $\gamma$ activity by approximately 2.0-2.3-fold, depending on the reporter genes, relative to PPAR $\gamma$ alone $(p<0.05)$. In addition, similar to the effect of NV-LJ3402-CM, CM from live LJ3402 also enhanced PPAR $\gamma$ activity. Furthermore, RT-qPCR showed that the mRNA levels of PPAR $\gamma$ and PPAR $\gamma$ target genes (ACOX and UCP1) were increased in day 8 3T3-L1 adipocytes treated with NV or live LJ3402-CM for $48 \mathrm{~h}$ ( $p<0.05$ vs. con, Figure 3c). However, on day 6, 3T3-L1 adipocytes were co-treated with LJ3402-CM and $10 \mu \mathrm{M}$ GW9662, a PPAR $\gamma$-specific antagonist, for $48 \mathrm{~h}$, the enhancing effect of LJ3402-CM on the expression of these genes was not observed, suggesting that LJ3402-CM may increase the expression of genes coding for proteins involved in energy dissipation by enhancing the PPAR $\gamma$ activity. Recent studies have shown that various thermogenic stimuli such as $\beta$-adrenergic stimulation, cold exposure, and PPAR $\gamma$ agonist treatment could trigger brown-like adipocytes in subcutaneous iWAT, leading to the suppression of fat accumulation in metabolic tissues by increasing the dissipation of energy as heat. PPAR $\gamma$ plays a key role in this process by upregulating the expression of UCP1, which is a key brown adipose tissue marker. As the NV-LJ3402-induced an increase in UCP1 and Cidea expression by enhancing PPAR $\gamma$ activity was already observed in the subcutaneous iWAT of HFD mice and 3T3-L1 adipocytes, the potential inhibitory effect of GW9662 on the NV-LJ3402-induced reduction in lipid accumulation in 3T3-L1 adipocytes was determined using Oil Red O staining. As expected, 48-h treatment of day 63 T3-L1 adipocytes with a browning stimulus (100 $\mu \mathrm{M}$ isoproterenol), live LJ3402-CM, and NV-LJ3402-CM reduced lipid accumulation by 70\%, 67\%, and $68 \%$, respectively, compared with that in the control adipocytes $(p<0.05$, Figure $3 \mathrm{~d})$. However, when cells were treated with GW9662 in the background of isoproterenol or LJ3402-CM treatment, the suppressive effect of isoproterenol and NV-LJ3402-CM on lipid accumulation was partially attenuated.

(a)

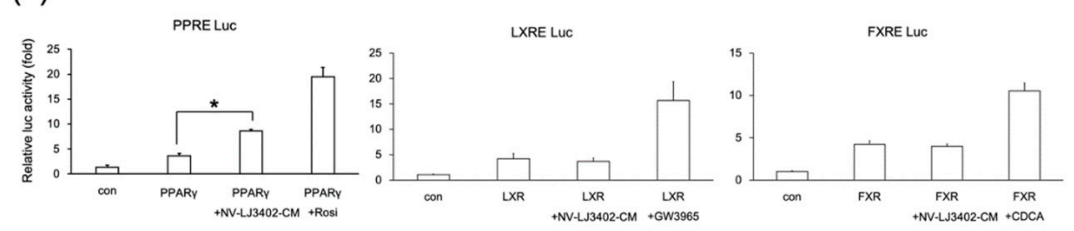

(b)

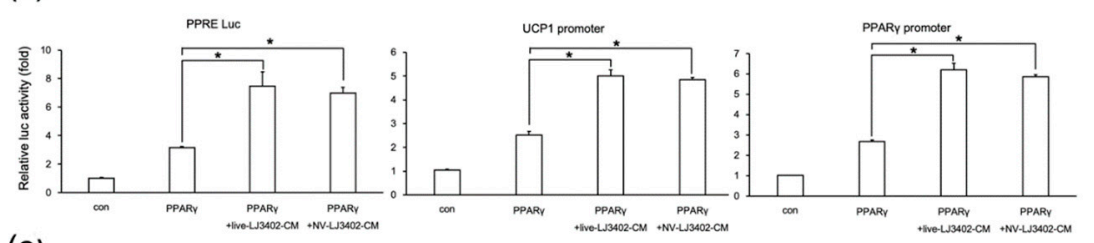

(c)

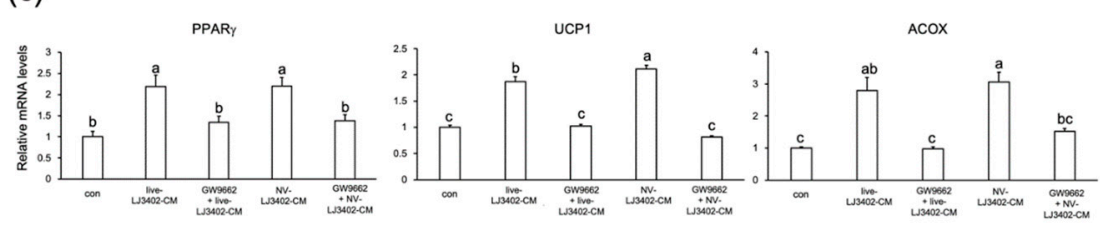

(d)

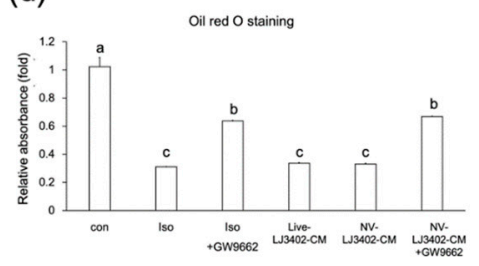

Figure 3. Effect of NV-LJ3402 on the activities of transcription factors important for metabolic gene expression (a) HEK293T cells were co-transfected with different metabolic transcription factors (PPAR $\gamma$, liver $\mathrm{X}$ receptor, $\mathrm{LXR}$ or farnesoid $\mathrm{X}$ receptor, FXR) and appropriate reporter genes harboring their cognate response elements (pGL3-ACOX-PPRE-Luc, PPRE Luc, pGL3-CETP-LXRE-luc, LXRE Luc or pGL3-TK-IR-1-Luc, FXRE Luc), as indicated. After 12-h transfection, cells were incubated for $24 \mathrm{~h}$ with 
either NV-LJ3402-CM, appropriate ligands, or vehicles (DMSO or con or both), as indicated, and then assayed for luciferase activity. (b) Effect of LJ3402-CM on PPAR $\gamma$ transcriptional activity was analyzed using various reporter genes harboring the PPAR $\gamma$ response element (pGL3-ACOX-PPRE-Luc) or different target gene promoters (pGL3-UCP1-Luc and pGL3-PPAR $\gamma$-Luc) in HEK293T cells. After 12-h transfection, cells were treated with con, live LJ3402-CM, and NV-LJ3402-CM as indicated. (c,d) Day 6 3T3-L1 adipocytes were incubated with live LJ3402-CM, NV-LJ3402-CM, isoproterenol (Iso, $100 \mu \mathrm{M}$ ) or GW9662 $(10 \mu \mathrm{M})$ or both for $48 \mathrm{~h}$, as indicated. The mRNA levels (c) of genes coding for proteins involved in energy dissipation and lipid accumulation (d) were analyzed by RT-qPCR and Oil Red O staining, respectively, as indicated. All data are expressed as the mean \pm S.E.M of three independent experiments. PPAR $\gamma$ vs. PPAR $\gamma+\mathrm{NV}-\mathrm{LJ} 3402 \mathrm{CM}$ or live LJ3402-CM, ${ }^{*} p<0.05$. Different lower-case letters above bars indicate significant differences $(p<0.05)$.

3.4. NV-LJ3402 Administration Enhances Mitochondrial Levels and Function in WATs Along with an Increase in Body Temperature in HFD Mice

Since UCP1 is a key molecule in mitochondrial thermogenesis, the effect of NV-LJ3402 on mitochondrial content was determined in the WATs of HFD mice and 3T3-L1 adipocytes. NV-LJ3402 increased the mtDNA copy number in WAT (iWAT and eWAT) of HFD-fed mice ( $p<0.05$ vs. HFD, Figure 4a). Furthermore, HFD-NV-LJ3402 mice also showed enhanced citrate synthase activity $(p<0.05$ vs. HFD), which is an indicator of mitochondrial function in WATs (Figure $4 \mathrm{~b}$ ). In addition, 48-h treatment of day 6 3T3-L1 adipocytes with NV-LJ3402-CM resulted in increased mtDNA copy number and citrate synthase activity ( $p<0.05$ vs. con), indicating that NV-LJ3402 can enhance the mitochondrial number and function in adipocytes (Figure 4c). Consistent with the NV-LJ3402-induced increase in mitochondrial number and function in the WAT of HFD-fed mice, HFD-NV-LJ3402 mice showed higher core body temperatures at $25^{\circ} \mathrm{C}(0 \mathrm{~h})$ and $4{ }^{\circ} \mathrm{C}(2-6 \mathrm{~h})$ than HFD mice. However, the effect of NV-LJ3402 on core body temperature was statistically meaningful only at 4-6 h cold exposure $(p<0.05)$. However, the effect of NV-LJ3402 on body temperature increase was significant $(p<0.05)$ after exposure to a temperature of $4{ }^{\circ} \mathrm{C}$ for $4 \mathrm{~h}$ (Figure $4 \mathrm{~d}$ ). Together, NV-LJ3402 increased the body temperature by enhancing thermogenesis by increased levels of mitochondria.

(a)
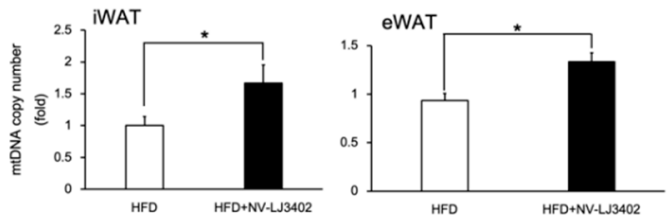

(b)
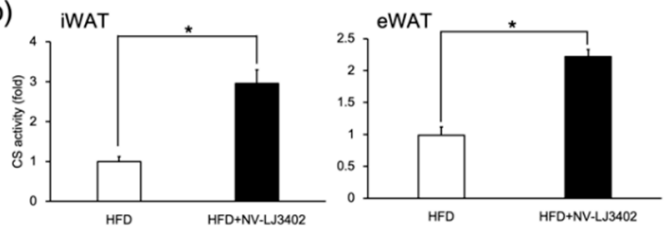

(c)

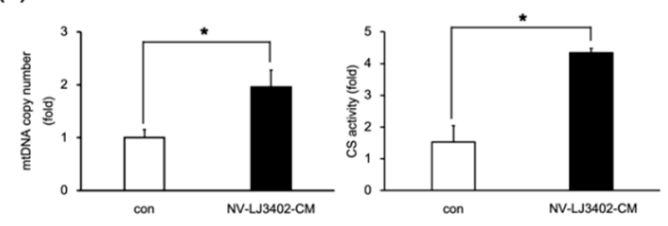

(d)

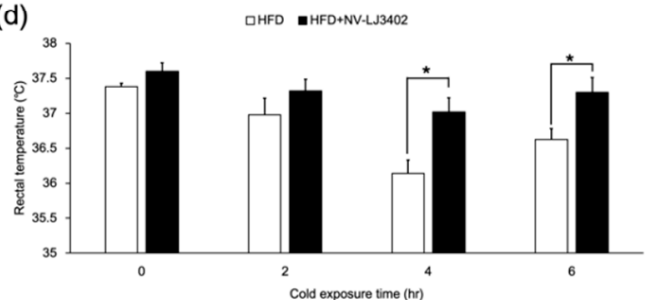

Figure 4. NV-LJ3402 enhances mitochondrial levels and increases the body temperature in HFD-fed mice. (a,b) Mitochondrial DNA (mtDNA) copy number (a) and citrate synthase activity (b) in inguinal WAT (iWAT) and eWAT of HFD and HFD-NV-LJ3402 mice ( $n=5-7$ per group). (c) Day 6 3T3-L1 adipocytes were treated with NV-LJ3402-CM for $48 \mathrm{~h}$, and then mtDNA copy number and citrate synthase activity were measured on day 8 , as indicated. mtDNA levels were normalized to those of nuclear genomic DNA. The results are from three independent experiments. (d) Core body temperature was measured based on rectal temperatures at $25^{\circ} \mathrm{C}(0 \mathrm{~h})$ and $4{ }^{\circ} \mathrm{C}$ for different durations $(2-6 \mathrm{~h})$ ( $n=7$ per group). All data are expressed as the mean \pm S.E.M. HFD vs. HFD+NV-LJ3402, con vs. NV-LJ3402-CM, ${ }^{*} p<0.05$. 


\subsection{Applicability of NV-LJ3042}

As shown in Table 2, the addition of NV-LJ3402 $\left(10^{8}\right.$ and $\left.10^{9}\right)$ did not affect the $\mathrm{pH}$ development and growth of the starter during yogurt fermentation.

Table 2. Changes of the $\mathrm{pH}$ value and the viable cells of lactic acid bacteria in yogurt fermentation.

\begin{tabular}{|c|c|c|}
\hline & $\begin{array}{l}\text { Initial Fermentation } \\
\quad(\text { Means } \pm \text { SD) }\end{array}$ & $\begin{array}{l}\text { Final Fermentation } \\
\quad(\text { Means } \pm \text { SD) }\end{array}$ \\
\hline Control & 6.49 & $4.5(4 \mathrm{~h} 31 \mathrm{~min}) *$ \\
\hline $\mathrm{pH}$ & $5.23 \times 10^{6} \pm 0.98$ & $1.68 \times 10^{9} \pm 1.06$ \\
\hline $\begin{array}{c}\text { S. thermophilus } \\
\text { L. bulgaricus subsp. bulgaricus }\end{array}$ & $4.83 \times 10^{6} \pm 1.71$ & $9.17 \times 10^{8} \pm 0.65$ \\
\hline $\begin{array}{c}\text { Non-viable L. johnsonii JNU3402 }\left(10^{8}\right) \\
\mathrm{pH}\end{array}$ & 6.52 & $4.5(4 \mathrm{~h} 27 \mathrm{~min}) *$ \\
\hline S. thermophilus & $5.07 \times 10^{6} \pm 1.11$ & $1.71 \times 10^{9} \pm 0.82$ \\
\hline L. bulgaricus subsp. bulgaricus & $4.65 \times 10^{6} \pm 1.62$ & $9.26 \times 10^{8} \pm 2.95$ \\
\hline Non-viable L. johnsonii JNU3402 $\left(10^{9}\right)$ & 6.54 & $4.5(4 \mathrm{~h} 24 \mathrm{~min}) *$ \\
\hline $\mathrm{pH}$ & $5.16 \times 10^{6} \pm 1.18$ & $1.37 \times 10^{9} \pm 0.65$ \\
\hline $\begin{array}{c}\text { S. thermophilus } \\
\text { L. bulgaricus subsp. bulgaricus }\end{array}$ & $4.37 \times 10^{6} \pm 0.95$ & $1.19 \times 10^{9} \pm 0.46$ \\
\hline
\end{tabular}

${ }^{*}$ Fermentation time to reach $\mathrm{pH} 4.5$.

The fermentation time to reach $\mathrm{pH} 4.5$ was shown to be $4 \mathrm{~h} 31 \mathrm{~min}$ (Control), $4 \mathrm{~h} 27 \mathrm{~min}$ (NV-LJ3402, $10^{8}$ ), and $4 \mathrm{~h} 24 \mathrm{~min}\left(\mathrm{NV}-\mathrm{LJ} 3402,10^{9}\right)$. With the addition of NV-LJ3402, the incubation time was a few minutes faster than that of the control. However, a few-minute difference does not hold significance in industrial applications.

After yogurt fermentation, the viable cells for S. thermophilus increased to $1.68 \times 10^{9}$ (Control), $1.71 \times 10^{9}\left(\mathrm{NV}-\mathrm{LJ} 3402,10^{8}\right)$, and $1.37 \times 10^{9} \mathrm{cfu} / \mathrm{mL}\left(\mathrm{NV}-\mathrm{LJ} 3402,10^{9}\right)$, respectively. Whereas, L. delbrueckii subsp. bulgaricus increased to $9.17 \times 10^{8}$ (Control), $9.26 \times 10^{8}\left(\mathrm{NV}-\mathrm{LJ} 3402,10^{8}\right)$, and $1.19 \times 10^{9} \mathrm{cfu} / \mathrm{mL}$ $\left(\mathrm{NV}-\mathrm{LJ} 3402,10^{9}\right)$, respectively. However, there was no significant differences in the viable cells of $S$. thermophilus and L. delbrueckii subsp. bulgaricus.

\section{Discussion}

Obesity is a major health problem in westernized societies because it is closely associated with various metabolic complications, including diabetes, hepatic steatosis, and cardiovascular diseases. Therefore, obesity prevention has important health benefits. Many studies have shown that several strains of probiotic bacteria could reduce insulin resistance and the incidence of diet-induced obesity, insulin resistance, diabetes, and fatty liver diseases [1]. Recent studies reported that two strains of Lactobacillus sp. exert a protective effect against diet-induced obesity by regulating hepatic fatty acid metabolism and inducing white adipose browning, respectively [3,4]. However, most studies investigating the effects of probiotics on host health, including these studies, have been performed using live bacteria. Although some reports have shown that NV probiotics play a role in the host immune system and reduce diet-induced obesity and insulin resistance [19-21], little is still known about the effect of NV probiotic bacteria on energy homeostasis in HFD-fed mice. Here, the effect of NV-LJ3402 on diet-induced obesity was examined, and the results demonstrated that NV-LJ3402 attenuates body weight gain and adiposity in HFD-fed mice by enhancing the expression of genes critical for energy dissipation in WAT.

Many studies have reported that chronic overnutrition causes alterations in the expression or activity of metabolic transcription factors or both, which results in the deregulation of the expression of their target genes, coding for proteins involved in energy metabolism, consequently leading to metabolic abnormalities such as obesity and diabetes [22]. Therefore, the administration of NV-LJ3402 may continuously attenuate HFD-induced deregulation of metabolic gene expression or activity, and 
this accumulated effect of NV-LJ3402 may protect against diet-induced obesity. Consistent with this assumption and the results of other studies $[3,4,23,24]$, continuous administration of NV-LJ3402 resulted in amelioration of diet-induced obesity in the later stages of HFD feeding. In this study, NV-LJ3402 upregulated the expression of PPAR $\gamma$ and its target genes that are important for energy dissipation (ACOX and UCP1) in WATs and downregulated the expression of lipogenic genes. Furthermore, both NV-LJ3402 CM and live LJ3402-CM increased the transcriptional activity of PPAR $\gamma$ to a similar extent in vitro-when reporter genes harboring the promoters of various PPAR $\gamma$ target genes were used-showing that both NV-LJ3402 and live LJ3402 could regulate the transcriptional activity of PPAR $\gamma$.

The inhibitory effect of NV-LJ3402 on HFD-induced deregulation of these metabolic genes suggests that NV-LJ3402 could also ameliorate the HFD-induced alterations in the metabolic parameters. NV-LJ3402 administration reduced TG levels in the plasma and metabolic tissues (liver and eWAT) in HFD mice. Additionally, NV-LJ3402 administration reduced glucose and insulin levels in the plasma and resulted in a slight improvement in glucose tolerance, indicating that NV-LJ3402 reduces lipid accumulation and insulin resistance in HFD mice. Furthermore, NV-LJ3402 administration increased the body temperature in HFD-fed mice. Since NV-LJ3402 also increased the mitochondria number in WAT and enhanced WAT expression of UCP1, which is known to release energy in the form of heat by uncoupling ATP production through proton leakage in mitochondria. These results suggest that the NV-LJ3402-induced decrease in TG levels and the reduction in obesity in HFD mice could be due to increased energy expenditure. In addition, NV-LJ3402-induced reduction of lipid accumulation in mature 3T3-L1 adipocytes was observed in parallel with an increase in mitochondrial content. Taken together, these findings demonstrated that NV probiotic bacteria, NV-LJ3402, could ameliorate metabolic disorders such as obesity, which are induced by HFD, and that this beneficial effect of NV-LJ3402 might promote the development of safe dairy products aimed at attenuating diet-induced obesity.

Author Contributions: E.K. and S.O. designed the study. G.Y. and E.H. performed the experiments and data analysis. E.K., S.O., and G.Y. wrote the manuscript. E.K. and S.O. reviewed the manuscript. All authors have read and agreed to the published version of the manuscript.

Funding: This research was supported by the Basic Science Program through the National Research Foundation of Korea (NRF) funded by the Ministry of Science, ICT, and Future Planning (NRF-2015R1A2A2A01007467) and the Ministry of Education (NRF-2018R1D1A1B07047076 and NRF-2019R1A2C108764811).

Conflicts of Interest: The authors declare no potential conflict of interest.

\section{References}

1. Xu, H.; Barnes, G.T.; Yang, Q.; Tan, G.; Yang, D.; Chou, C.J.; Sole, J.; Nichols, A.; Ross, J.S.; Tartaglia, L.A.; et al. Chronic inflammation in fat plays a crucial role in the development of obesity-related insulin resistance. J. Clin. Investig. 2003, 112, 1821-1830. [CrossRef] [PubMed]

2. Dahiya, D.K.; Renuka; Puniya, M.; Shandilya, U.K.; Dhewa, T.; Kumar, N.; Kumar, S.; Puniya, A.K.; Shukla, P. Gut Microbiota Modulation and Its Relationship with Obesity Using Prebiotic Fibers and Probiotics: A Review. Front. Microbiol. 2017, 8, 563. [CrossRef] [PubMed]

3. Park, S.S.; Lee, Y.J.; Song, S.; Kim, B.; Kang, H.; Oh, S.; Kim, E. Lactobacillus acidophilus NS1 attenuates diet-induced obesity and fatty liver. J. Endocrinol. 2018, 237, 87-100. [CrossRef] [PubMed]

4. $\quad$ Park, S.S.; Lee, Y.J.; Kang, H.; Yang, G.; Hong, E.J.; Lim, J.Y.; Oh, S.; Kim, E. Lactobacillus amylovorus KU4 ameliorates diet-induced obesity in mice by promoting adipose browning through PPARgamma signaling. Sci. Rep. 2019, 9, 20152. [CrossRef] [PubMed]

5. FAO/WHO. Guidelines for the Evaluation of Probiotics in Food. In Proceedings of the Food and Agriculture Organization of the United Nations and World Health Organization Working Group Report, London, ON, Canada, 30 April-1 May 2002; pp. 1-11.

6. Villena, J.; Barbieri, N.; Salva, S.; Herrera, M.; Alvarez, S. Enhanced immune response to pneumococcal infection in malnourished mice nasally treated with heat-killed Lactobacillus casei. Microbiol. Immunol. 2009, 53, 636-646. [CrossRef] [PubMed] 
7. Pique, N.; Berlanga, M.; Minana-Galbis, D. Health Benefits of Heat-Killed (Tyndallized) Probiotics: An Overview. Int. J. Mol. Sci. 2019, 20, 2534. [CrossRef] [PubMed]

8. Fernandes, R. Microbiology handbook. Dairy products; Leatherhead Pub. and Royal Society of Chemistry: Cambridge, UK, 2009.

9. Zheng, J.; Wittouck, S.; Salvetti, E.; Franz, C.; Harris, H.M.B.; Mattarelli, P.; O’Toole, P.W.; Pot, B.; Vandamme, P.; Walter, J.; et al. A taxonomic note on the genus Lactobacillus: Description of 23 novel genera, emended description of the genus Lactobacillus Beijerinck 1901, and union of Lactobacillaceae and Leuconostocaceae. Int. J. Syst. Evol. Microbiol. 2020, 70, 2782-2858. [CrossRef]

10. Buhnik-Rosenblau, K.; Matsko-Efimov, V.; Jung, M.; Shin, H.; Danin-Poleg, Y.; Kashi, Y. Indication for Co-evolution of Lactobacillus johnsonii with its hosts. BMC Microbiol. 2012, 12, 149. [CrossRef]

11. Fonseca, W.; Lucey, K.; Jang, S.; Fujimura, K.E.; Rasky, A.; Ting, H.A.; Petersen, J.; Johnson, C.C.; Boushey, H.A.; Zoratti, E.; et al. Lactobacillus johnsonii supplementation attenuates respiratory viral infection via metabolic reprogramming and immune cell modulation. Mucosal Immunol. 2017, 10, 1569-1580. [CrossRef]

12. Fukushima, Y.; Miyaguchi, S.; Yamano, T.; Kaburagi, T.; Iino, H.; Ushida, K.; Sato, K. Improvement of nutritional status and incidence of infection in hospitalised, enterally fed elderly by feeding of fermented milk containing probiotic Lactobacillus johnsonii La1 (NCC533). Br. J. Nutr. 2007, 98, 969-977. [CrossRef]

13. Choi, H.; Kim, S.J.; Park, S.S.; Chang, C.; Kim, E. TR4 activates FATP1 gene expression to promote lipid accumulation in 3T3-L1 adipocytes. FEBS Lett. 2011, 585, 2763-2767. [CrossRef] [PubMed]

14. Park, S.S.; Choi, H.; Kim, S.J.; Chang, C.; Kim, E. CREB/GSK-3beta signaling pathway regulates the expression of TR4 orphan nuclear receptor gene. Mol. Cell. Endocrinol. 2016, 423, 22-29. [CrossRef] [PubMed]

15. Park, S.S.; Choi, H.; Kim, S.J.; Kim, O.J.; Chae, K.S.; Kim, E. FXRalpha down-regulates LXRalpha signaling at the CETP promoter via a common element. Mol. Cells 2008, 26, 409-414. [PubMed]

16. Soukoulis, C.; Panagiotidis, P.; Koureli, R.; Tzia, C. Industrial yogurt manufacture: Monitoring of fermentation process and improvement of final product quality. J. Dairy Sci. 2007, 90, 2641-2654. [CrossRef]

17. Depommier, C.; Everard, A.; Druart, C.; Plovier, H.; Van Hul, M.; Vieira-Silva, S.; Falony, G.; Raes, J.; Maiter, D.; Delzenne, N.M.; et al. Supplementation with Akkermansia muciniphila in overweight and obese human volunteers: A proof-of-concept exploratory study. Nat. Med. 2019, 25, 1096-1103. [CrossRef]

18. Carmiel-Haggai, M.; Cederbaum, A.I.; Nieto, N. A high-fat diet leads to the progression of non-alcoholic fatty liver disease in obese rats. FASEB J. 2005, 19, 136-138. [CrossRef]

19. Cani, P.D.; de Vos, W.M. Next-Generation Beneficial Microbes: The Case of Akkermansia muciniphila. Front. Microbiol. 2017, 8, 1765. [CrossRef]

20. Depommier, C.; Van Hul, M.; Everard, A.; Delzenne, N.M.; De Vos, W.M.; Cani, P.D. Pasteurized Akkermansia muciniphila increases whole-body energy expenditure and fecal energy excretion in diet-induced obese mice. Gut Microbes 2020, 11, 1231-1245. [CrossRef]

21. Plovier, H.; Everard, A.; Druart, C.; Depommier, C.; Van Hul, M.; Geurts, L.; Chilloux, J.; Ottman, N.; Duparc, T.; Lichtenstein, L.; et al. A purified membrane protein from Akkermansia muciniphila or the pasteurized bacterium improves metabolism in obese and diabetic mice. Nat. Med. 2017, 23, 107-113. [CrossRef]

22. Longo, M.; Zatterale, F.; Naderi, J.; Parrillo, L.; Formisano, P.; Raciti, G.A.; Beguinot, F.; Miele, C. Adipose Tissue Dysfunction as Determinant of Obesity-Associated Metabolic Complications. Int. J. Mol. Sci. 2019, 20, 2358. [CrossRef]

23. Cheng, Y.C.; Liu, J.R. Effect of Lactobacillus rhamnosus GG on Energy Metabolism, Leptin Resistance, and Gut Microbiota in Mice with Diet-Induced Obesity. Nutrients 2020, 12, 2557. [CrossRef]

24. Hsieh, M.C.; Tsai, W.H.; Jheng, Y.P.; Su, S.L.; Wang, S.Y.; Lin, C.C.; Chen, Y.H.; Chang, W.W. The beneficial effects of Lactobacillus reuteri ADR-1 or ADR-3 consumption on type 2 diabetes mellitus: A randomized, double-blinded, placebo-controlled trial. Sci. Rep. 2018, 8, 16791. [CrossRef]

Publisher's Note: MDPI stays neutral with regard to jurisdictional claims in published maps and institutional affiliations. 